\title{
Epidemiology of sick building syndrome and its associated risk factors in Singapore
}

\author{
P L Ooi, K T Goh, M H Phoon, S C Foo, H M Yap
}

\begin{abstract}
Objectives-To investigate the occurrence of sick building syndrome in a tropical city, and its relation to indoor air quality and other factors.

Methods-2856 office workers in 56 randomly selected public and private sector buildings were surveyed. The study consisted of a self administered questionnaire assessing symptoms and perception of the physical and psychosocial environment, inspection of the building plans and premises, and measurement of temperature, relative humidity, respirable particles, chemicals, bioaerosols, and other variables.

Results-Symptoms typical of the sick building syndrome were reported in $19.6 \%$ of the respondents. Multivariate modelling substantiated contributions associated with low thermal comfort, high work related stress, too much noise, a history of allergy or other medical conditions, poor lighting, young employees, and female sex. Measurements of indoor air quality or ventilation were not found to be reliable predictors of the symptoms.

Conclusion-The survey confirmed the presence of sick building syndrome and its risk factors in the tropics. A biopsychosocial approach to the problem involving symptomatic treatment, environmental control, good ergonomic design, and stress management is recommended.
\end{abstract}

(Occup Environ Med 1998;55:188-193)

Institute of

Environmental

Epidemiology,

Ministry of the

Environment,

Singapore

P L Ooi

K T Goh

M H Phoon

Department of

Community,

Occupational, and

Family Medicine,

National University of

Singapore

S C Foo

H M Yap

Correspondence to:

Dr Ooi P L, Institute of

Environmental

Epidemiology, Ministry of

the Environment, 40 Scotts

Road 22-00, Singapore

228231 .

Accepted 22 August 1997
Ministry of the Environment initiated a ease and the distribution of the causative surveillance programme on legionnaires' dis- bacteria in the cooling towers. ${ }^{56}$ This was followed in 1992 by the publication of a code of practice for use by building owners and management corporations in the servicing and maintenance of air conditioning cooling towers. ${ }^{7}$ Other illnesses associated with buildings continue to be investigated. ${ }^{89}$ Although the cause of most building related symptoms remained unknown, the increasing reliance on artificial ventilation has fueled a widespread perception of indoor air pollution as the problem. ${ }^{1011}$

The sick building syndrome is a major concern because of the many people potentially at risk. It was defined by the World Health Organisation (WHO) as an excess of work related irritations of the skin and mucous membranes and other symptoms, including headache, fatigue, and difficulty concentrating, reported by workers in modern office buildings. ${ }^{12}$ The condition had been well documented in the temperate countries where it was considered a major cause of sickness absenteeism and lost productivity among the workers. ${ }^{13}{ }^{14}$ As baseline data in the tropics were lacking, we conducted a nationwide morbidity survey involving 2856 office workers in 56 randomly selected public and private sector buildings. The objective was to investigate the occurrence of sick building syndrome and its relation to indoor air quality and other factors.

\section{Methods}

Our multidisciplinary team included two medical epidemiologists, an industrial hygienist, an engineer, a chemist, a microbiologist, two research assistants, and two health officers. In 1992-5, the stages of work involved survey design, administration of a standardised questionnaire assessing symptoms and perception of the physical and psychosocial environment, walk through inspections of the buildings, measurements of the indoor climate, and statistical analyses of the data.

The subjects in the study were recruited from a source population of all public and private buildings inside and outside Central Business District, the commercial and financial hub of Singapore. We used a randomised multistage cluster sampling procedure. Figure 1 shows the details of the procedure and results, including restrictions and losses of premises and people. The 56 building owners and 127 office managers or employers were approached individually to obtain consent for inclusion of their premises as part of the survey. The participation rate for the selected buildings was $100 \%$, but that for offices was $99.2 \%$ (one private sector office which had agreed to cooperate 
Source population of all office buildings

in Singapore stratified into public and private sector buildings

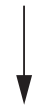

56 Office buildings

( 6 public and 50 private sector)

drawn at random and invited to participate

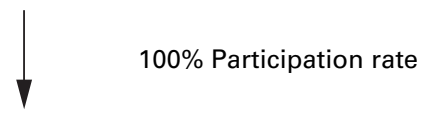

127 Offices (67 public and 60 private sector) within the selected buildings

drawn at random and invited to participate

99.2\% Participation rate

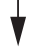

All 3829 staff

(2931 public and 898 private sector)

within the selected offices

invited to respond to the questionnaire

$$
\text { 74.6\% Response rate }
$$

Questionnaires returned by 2856 respondents

(2160 public and 666 private sector)

$$
\begin{aligned}
& 30 \text { Questionnaires found to be } \\
& \text { incomplete }
\end{aligned}
$$

Findings from remaining 2826 questionnaires analysed (364 respondents with symptoms attributable to known medical conditions, 554 respondents with symptoms of uncertain aetiology related to buildings, and 1908 non-affected respondents)

Figure 1 Randomised multistage cluster sampling procedure showing restrictions and losses of premises and people. count for their symptoms - for example, current respiratory infection, pregnancy-but not those with known illness that were free from acute exacerbations at the time of the survey. We used criteria compatible with the WHO definition for a case of sick building syndrome (onset of two or more symptoms at least twice weekly while in the building), overnight resolution of these symptoms after leaving the building or workstation, and absence of known medical causes.

Supplementary data were obtained by walk through inspections of the buildings and monitoring of indoor air quality. Although we attempted to reduce any delay between the administration of the questionnaires and these activities as much as possible, a time lag of one to three weeks was usually noted because of logistic and administrative issues. With a building checklist and floor plans, we carried out detailed inspection of the offices, ventilation systems, and other facilities. The offices were typically equipped with central air conditioning, fluorescent lighting, and wall to wall carpeting and comprised open concept workstations for junior staff and a few enclosed rooms for senior staff. We confirmed that smoking was prohibited in all the premises, and no renovation work was in progress. Table 1 shows the indoor variables investigated, types of analytical instruments used, and their detection limits. Indoor air samples were collected from the breathing zone, about $1.4 \mathrm{~m}$ above the floor, at over 285 locations within the premises based on approved methods. ${ }^{15-17}$ Reference outdoor samples were taken from fresh air intake points located in the air handling rooms of the buildings.

For the statistical analyses, unmatched controls were drawn from the non-affected respondents at over three times the number of cases to ensure adequate statistical power. Differences in the distribution of risk factors between cases and controls were firstly compared by the $\chi^{2}$ test, and odds ratios with $95 \%$ confidence intervals derived. ${ }^{18}$ In our exploratory data analysis, we also divided the symptoms into subgroups to assess their correlation with specific risk factors. The contaminant concentrations of the offices, and between the indoor and outdoor air, were compared by the non-parametric Mann Whitney $U$ test. Significant variables were then subjected to multiple logistic regression modelling to simultaneously adjust for potentially confounding covariates. ${ }^{19}$ Stepwise selection was used to eventually develop a final model that might explain the occurrence of symptoms in our study population. The fit of this model was next assessed by the log likelihood and Hosemer and Lemeshow tests. All computations were performed with Epi Info (Centers for Disease Control and Prevention, Georgia), SPSS (SPSS, Illinois) and SAS (SAS Institute, North Carolina) software.

\section{Results}

The final sample consisted of 2856 workers $(74.6 \%$ response) drawn from 126 offices within 56 buildings located throughout the island (fig 1). As 30 of the questionnaires were syndrome, we excluded subjects with preexisting medical conditions which could ac- 
returned incomplete, this paper is based on the remaining 2826 respondents. The respondents comprised $2160(76.4 \%)$ public and 666 $(23.6 \%)$ private sector employees, with ages ranging from 16 to $\geqslant 60$. Women outnumbered men by a ratio of 3:2. The racial composition, comprising $79 \%$ Chinese, $12 \%$ Malays, $7 \%$ Indians, and $2 \%$ others, closely mirrored that of the Singapore population.

After excluding 364 (12.9\%) respondents with health complaints attributable to known medical conditions, 554 (19.6\%) reported frequent building related symptoms of uncertain aetiology. Figure 2 shows a frequency distribution of the proportion of affected workers within the different buildings. The symptoms were fatigue $(12.3 \%)$, dry throat $(10.9 \%)$, eye irritation $(9.1 \%)$, stuffy nose $(8.7 \%)$, drowsiness $(8.3 \%)$, headache $(7.1 \%)$, skin dryness or rash $(4.8 \%)$, dizziness $(2.8 \%)$, shortness of breath $(2.3 \%)$, and nausea or vomiting $(0.5 \%)$. A quarter $(25.5 \%)$ of these cases thought that their symptoms occurred more in the afternoon whereas most did not notice a trend in time. These symptoms were generally not severe; the cases recorded a mean of 0.6 days (range 0-10 days) medical leave over a four week period compared with 0.2 days (range 0-7 days) for other occupants. This difference was not significant.

Table 2 shows the prevalence of personal and perceived environmental factors in relation to the building related symptoms. The multiple associations were consistent when we analysed subsamples of public and private sector office workers and varied the case definition from two or more symptoms to at least one symptom. Most of these factors remained significant independent determinants of the risks of building related symptoms even after adjustment for confounding (table 3 ). The multiple logistic regression modelling substantiated contributions associated with low thermal

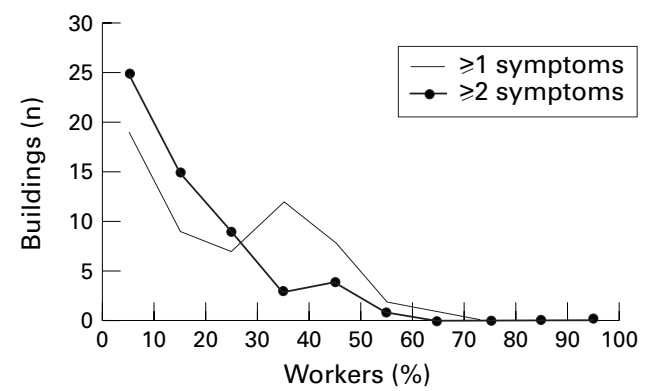

Figure 2 Frequency distribution of the proportion of workers reporting symptoms related to buildings from 56 office buildings in Singapore.

comfort, high work related stress, too much noise, a history of allergy or other medical conditions, poor lighting, young employees, and female sex. No collinearity in the independent variables was found. Criteria for assessing our final model suggested that the fit was satisfactory $(\mathrm{p}<0.001)$.

We did not find measurements of indoor air quality or ventilation to be reliable predictors of the symptoms. The indoor variables monitored in the vicinity of most complainants remained largely within acceptable limits (table 4 ). The commonest air pollutants detected during the workshift were formaldehyde emissions from new furnishings containing formaldehyde based resins, and carbon dioxide from human respiration. Up to $15 \%$ of the offices showed inadequate ventilation contributing to build ups in excess of $120 \mu \mathrm{g} / \mathrm{m}^{3}$ and $1000 \mathrm{ppm}$, respectively. Although low thermal comfort had been implicated in the questionnaire survey, we noted no obvious relation of symptoms with fluctuations of temperature, relative humidity, and air movement beyond recommended levels. ${ }^{20}$ The correlation between symptom subgroups and measured exposures was also poor. Walk through inspections showed that the buildings were satisfactorily maintained with no major irregularities that

Table 1 Indoor variables investigated, analytical methods used, and their detection limits

\begin{tabular}{|c|c|c|c|}
\hline Variable & Methods & Instruments & Detection limit \\
\hline Carbon dioxide & Non-dispersive infrared spectroscopy & $\begin{array}{l}\text { GFC model } 41 / 41 \mathrm{H} \text { carbon dioxide } \\
\text { analyser, Metrosonic aq502 indoor } \\
\text { environment monitor }\end{array}$ & $0.01 \mathrm{ppm}$ \\
\hline Carbon monoxide & Non-dispersive infrared spectroscopy, voltage toxic electrochemical sensor & $\begin{array}{l}\text { GFC model } 48 \text { carbon monoxide } \\
\text { analyser, Metrosonic aq502 indoor } \\
\text { environment monitor }\end{array}$ & $0.1 \mathrm{ppm}$ \\
\hline Ozone & Ultraviolet photometry & $\begin{array}{l}\text { Thermo environmental model } 49 \\
\text { ambient ozone analyser }\end{array}$ & $0.01 \mathrm{ppm}$ \\
\hline $\begin{array}{l}\text { Volatile organic } \\
\text { compounds }\end{array}$ & $\begin{array}{l}\text { Thermal desorption with gas chromatography-mass spectrometry, } \\
\text { photoionisation at } 10.6 \mathrm{eV}\end{array}$ & $\begin{array}{l}\text { OI-Analytical } 4460 \mathrm{~A}, \mathrm{HP} 5890 \text { gas } \\
\text { chromatograph, HP } 5988 \text { mass } \\
\text { spectrometer, Photovac Microtip } \\
\text { MP } 1000 \text { photoionisation detector }\end{array}$ & $0.01 \mathrm{ppm}$ \\
\hline Formaldehyde & Solid adsorbent sampling with high performance liquid chromatography & $\begin{array}{l}\text { DNPH Sep-Pak cartridges, Shimadzu } \\
\text { HPLC (UV-vis detector), HP1090 liquid } \\
\text { chromatograph }\end{array}$ & $0.5 \mu \mathrm{g} / \mathrm{m}^{3}$ \\
\hline Respirable particles & Continous mass monitoring, piezoelectric microbalance & $\begin{array}{l}\text { Model PC2 aerosol particle analyser, } \\
\text { Kanomax Model } 3511 \text { respirable aerosol } \\
\text { mass monitor }\end{array}$ & $0.01 \mu \mathrm{g} / \mathrm{m}^{3}$ \\
\hline Heat stress & Black globe and natural dry bulb sensor & Metrosonic hs 360 heat stress monitor & $0.1^{\circ} \mathrm{C}$ \\
\hline Air temperature & Resistance thermal detector & $\begin{array}{l}\text { Metrosonic aq502 indoor environment } \\
\text { monitor }\end{array}$ & $0.1^{\circ} \mathrm{C}$ \\
\hline Relative humidity & Capacitance sensor & $\begin{array}{l}\text { Metrosonic aq502 indoor environment } \\
\text { monitor }\end{array}$ & $0.1 \%$ \\
\hline Air movement & Hot wire anemometry & Kanomax model 24-6111 anemometer & $0.01 \mathrm{~m} / \mathrm{s}$ \\
\hline Noise & Equivalent continuous sound level $\left(\mathrm{L}_{\mathrm{eq}}\right)$, A weighted & Bruel and Kjaer 4436 noise dose meter & $0.1 \mathrm{dBA}$ \\
\hline Lighting & Photocell & $\begin{array}{l}\text { Metrosonic aq502 indoor environment } \\
\text { monitor }\end{array}$ & 1 lux \\
\hline Total bacterial counts & Tryptic soy agar culture & Andersen N6 single stage impactor & $1 \mathrm{CFU} / \mathrm{m}^{3}$ \\
\hline Total fungal counts & Potato dextrose/rose bengal streptomycin agar culture & Andersen N6 single stage impactor & $1 \mathrm{CFU} / \mathrm{m}^{3}$ \\
\hline
\end{tabular}


Table 2 Univariate analysis of prevalence of personal and environmental risk factors for symptoms related to buildings

\begin{tabular}{|c|c|c|c|}
\hline Study variable & Cases $(n=554)$ & Controls $(n=1908)$ & OR $(95 \% C I)^{*}$ \\
\hline \multicolumn{4}{|l|}{ Sex: } \\
\hline Female & 371 & 1054 & $1.64(1.34$ to 2.01$)$ \\
\hline \multicolumn{4}{|l|}{ Age $(y): \dagger$} \\
\hline $16-25$ & 136 & 306 & $1.70(1.34$ to 2.15$)$ \\
\hline $26-35$ & 195 & 572 & $1.27(1.03$ to 1.56$)$ \\
\hline $36-45$ & 114 & 540 & $0.66(0.52$ to 0.83$)$ \\
\hline$>45$ & 30 & 237 & $0.40(0.27$ to 0.61$)$ \\
\hline \multicolumn{4}{|l|}{ Race: } \\
\hline Chinese & 435 & 1521 & $0.93(0.73$ to 1.18$)$ \\
\hline Malay & 65 & 205 & $1.10(0.81$ to 1.50$)$ \\
\hline Indian & 36 & 116 & $1.07(0.71$ to 1.61$)$ \\
\hline \multicolumn{4}{|l|}{ History of a medical condition: } \\
\hline Sinus problems & 115 & 187 & $2.41(1.85$ to 3.14$)$ \\
\hline Migraine & 118 & 201 & $2.30(1.78$ to 2.98$)$ \\
\hline Allergies (including asthma) & 82 & 134 & $2.30(1.70$ to 3.11$)$ \\
\hline \multicolumn{4}{|l|}{ Job grade: } \\
\hline Senior staff (managerial, professional) & 191 & 664 & $0.99(0.80$ to 1.21$)$ \\
\hline Secretarial & 25 & 76 & $1.14(0.70$ to 1.85$)$ \\
\hline Clerical & 194 & 674 & $0.99(0.81$ to 1.21$)$ \\
\hline Other (technical, uniformed) & 144 & 494 & $1.01(0.81$ to 1.25$)$ \\
\hline \multicolumn{4}{|l|}{ Work related experiences: } \\
\hline Long hours daily ( $>8 \mathrm{~h}$ ) & 98 & 243 & $1.47(1.13$ to 1.92$)$ \\
\hline High stress level at work & 294 & 555 & $2.75(2.26$ to 3.36$)$ \\
\hline \multicolumn{4}{|l|}{ Thermal comfort at workstation: } \\
\hline Extreme cold requiring extra clothing for comfort & 161 & 327 & $1.98(1.58$ to 2.48$)$ \\
\hline Insufficient air movement & 267 & 443 & $3.08(2.51$ to 3.77$)$ \\
\hline Stuffiness & 119 & 112 & $4.39(3.29$ to 5.85$)$ \\
\hline \multicolumn{4}{|l|}{ Other environmental exposures: } \\
\hline Too much noise & 173 & 316 & $2.29(1.83$ to 2.86$)$ \\
\hline Poor lighting & 88 & 141 & $2.37(1.76$ to 3.18$)$ \\
\hline Use of visual display unit & 307 & 876 & $1.46(1.21$ to 1.78$)$ \\
\hline \multicolumn{4}{|l|}{ Type of office building: } \\
\hline Public sector & 437 & 1485 & $1.06(0.84$ to 1.35$)$ \\
\hline Private sector & 117 & 423 & $0.94(0.74$ to 1.19$)$ \\
\hline
\end{tabular}

^ In the interpretation of ORs, the value for each specific category - for example 1.7 for age-group 16-25 years-is obtained in comparison with all other categories (all other age groups).

† This variable was missing for 79 cases and 253 controls.

could affect air quality by releasing pollutants or reducing ventilation. The detailed methodology and results of these investigations will be published elsewhere.

Table 3 Multivariate analysis (logistic regression model) of significant determinants predicting the sick building syndrome

\begin{tabular}{lll}
\hline Significant determinant & Adjusted OR $(95 \% \text { CI })^{\star}$ & $p$ Value \\
\hline Low thermal comfort at workstation & $2.84(2.31$ to 3.51$)$ & 0.0001 \\
High stress level at work & $2.41(1.96$ to 2.96$)$ & 0.0001 \\
Too much noise & $2.06(1.63$ to 2.61$)$ & 0.0001 \\
History of a medical condition & $1.89(1.51$ to 2.35$)$ & 0.0001 \\
Poor lighting & $1.83(1.34$ to 2.49$)$ & 0.0001 \\
Young employee (16-25 y) & $1.57(1.22$ to 2.03$)$ & 0.0001 \\
Female & $1.31(1.05$ to 1.63$)$ & 0.0161 \\
\hline
\end{tabular}

*Adjusted for mutual confounding between significant independent variables (thermal comfort, stress experience, noise, medical condition, lighting, 16-25 year age-group, and sex).

Table 4 Summary of analytical results for selected indoor variables monitored within 56 air conditioned office buildings in Singapore

\begin{tabular}{|c|c|c|c|c|c|}
\hline Variable & $\begin{array}{l}\text { Sampling } \\
\text { time }\end{array}$ & $\begin{array}{l}\text { Locations } \\
\text { (n) }\end{array}$ & Mean value & Lower limit & Upper limit \\
\hline Carbon dioxide (ppm) & $6-8 \mathrm{~h}$ & 228 & 808 & 350 & 1560 \\
\hline Carbon monoxide (ppm) & $6-8 \mathrm{~h}$ & 228 & 1 & 0.1 & 5 \\
\hline Ozone (ppm) & $6-8 \mathrm{~h}$ & 48 & 0.05 & 0.01 & 0.47 \\
\hline $\begin{array}{l}\text { Volatile organic } \\
\text { compounds (ppm) }\end{array}$ & $6-8 \mathrm{~h}$ & 79 & 1.9 & 0.03 & 37.8 \\
\hline Formaldehyde $\left(\mu \mathrm{g} / \mathrm{m}^{3}\right)$ & $6-8 \mathrm{~h}$ & 266 & 34 & 2 & 271 \\
\hline Respirable particles & & & & & \\
\hline$\left(\mu \mathrm{g} / \mathrm{m}^{3}\right)$ & $6-8 \mathrm{~h}$ & 180 & 23 & 0.2 & 120 \\
\hline Heat stress $\left({ }^{\circ} \mathrm{C}\right)$ & $6-8 \mathrm{~h}$ & 180 & 0.4 & 0.1 & 0.6 \\
\hline Air temperature $\left({ }^{\circ} \mathrm{C}\right)$ & $6-8 \mathrm{~h}$ & 285 & 23 & 19 & 27 \\
\hline Relative humidity (\%) & $6-8 \mathrm{~h}$ & 285 & 64 & 41 & 89 \\
\hline Air movement $(\mathrm{m} / \mathrm{s})$ & $6-8 \mathrm{~h}$ & 180 & 0.1 & 0.05 & 0.83 \\
\hline Noise (dBA) & $6-8 \mathrm{~h}$ & 180 & 59 & 56 & 62 \\
\hline Lighting (lux) & $6-8 \mathrm{~h}$ & 228 & 513 & 197 & 822 \\
\hline $\begin{array}{l}\text { Total bacterial counts } \\
\left(\mathrm{CFU} / \mathrm{m}^{3}\right)\end{array}$ & $4 \mathrm{~min}$ & 76 & 204 & 19 & 1360 \\
\hline $\begin{array}{l}\text { Total fungal counts } \\
\left(\mathrm{CFU} / \mathrm{m}^{3}\right)\end{array}$ & $4 \min$ & 76 & 63 & 5 & 1062 \\
\hline
\end{tabular}

\section{Discussion}

Singapore has well established outdoor air quality standards, ${ }^{21}$ but they have had little impact on indoor air quality. This is because the types and sources of pollutants found indoors remain quite different from those outdoors. The need to minimise the risk of health effects arising from poor indoor air quality is made more acute by the fact that people spend much more time indoors than outdoors. To improve the indoor air quality within office premises, the Ministry of the Environment has published guidelines on conducting periodic building inspections, obtaining feedback from the occupants, and monitoring indoor air variables. ${ }^{22}$ These guidelines were based on our three year study and it was intended that building owners periodically gauge their indoor air quality and if necessary, upgrade their maintenance or undertake further remedial action.

We found that at any one time, at least one in five workers could be expected to have health complaints which were attributed to the building. The ailments included general or neurotoxic reactions (fatigue, headache, drowsiness, dizziness), eye irritation, irritation of the nose, throat, and airway (stuffy nose, dry throat, shortness of breath), skin irritation (dryness, rash), and other complaints (nausea, vomiting). These building related symptoms were non-specific and had many possible causes. ${ }^{13}$ None the less, a consistent temporal relation could be established with symptoms which increased or became more apparent over the workshift and which resolved upon leaving the premises. This feature resembled symptoms 
reported in the sick building syndrome of temperate countries. As there is no definitive diagnosis for the condition-for example, by immunological or biochemical tests - we found that the prevalence of the syndrome among office workers could vary with the specificity of criteria used to define a case, and with the degree of investigation to exclude other causes. This was demonstrable by a shift in the frequency distribution of the proportion of affected workers within the different buildings when we changed the criteria from two or more symptoms to at least one symptom. Hence, empirical definitions of the syndrome based on a proportion-for example, in excess of $20 \%$ $30 \%$ of workers in the building being affected-were not too helpful.

The consistent temporal relation between the symptoms and the air conditioned office premises substantiated the important role of the physical environment in the aetiology of ailments. However, it was uncertain whether the pollutants detected had contributed to the symptoms because the only significant relations between sick building syndrome and environmental factors were found for perceived indoor air exposure reported in the questionnaire, and not objective measurements of these factors in the office. Unlike industrial settings where evaluation can be directed by chemical analysis of the materials used by or in the vicinity of the affected workers, it would be extremely difficult and costly to characterise all exposures and their health effects within the office environment.

The exact mechanisms triggering the health complaints are still not fully understood, but one important determinant seemed related to the perception of low environmental comfort among the occupants. These thermal comfort, lighting, and acoustic problems pointed to an urgent need for more ergonomically sound designs of the workplace. A lack of control over the thermal climate, for example, may not in itself be as serious as air pollution, but could cause significant distress and affect an occupant's perception of the workplace, particularly if the temperature and humidity often fluctuated as adjustments were attempted. ${ }^{8}$ Similarly, problems related to inappropriate lighting have been implicated in studies of the sick building syndrome. ${ }^{2324}$

Certain limitations in our study might have contributed to the lack of correlation between sick building syndrome and measured exposures. Firstly, because of a one to three week time lag between the administration of questionnaires and the indoor air measurements, we could not exclude the possibility that a causative agent for symptoms that were reported in the questionnaire may have been ventilated out of the building before indoor air sampling began. Secondly, we relied exclusively on self reported symptoms and did not include examination by a physician to verify the actual extent of illness among those exposed. In the absence of clinical consensus on what constituted sick building syndrome, our case definition could have inadvertently excluded some sensitive subjects. Finally, as with any retro- spective survey, bias might lie in the selective recall of details by cases. Those affected usually search their memories for an exposure in an attempt to explain or understand why they acquired the illness, which would cause more of an association to be found between symptoms and perceived exposures than measured exposures.

It is likely that the larger number of cases identified among young employees was the result of an environmental adaptation and self selection process operating in the older employees who had worked longer. Over time, as workers who were unable to adapt continued to leave employment because of ill health or other complaints, a healthy worker effect probably emerged among those who stayed behind. The potential presence of these other risk factors suggested that, besides expending scientific effort on environmental measurement, we should continue to identify markers of individual susceptibility. ${ }^{25-27}$

The inability of indoor air quality measurements to reliably predict the sick building syndrome indicated some influence exerted by personal and psychosocial variables on the person's health status and health seeking behaviour. A predisposing factor among cases seemed to be concurrent medical conditions which increased their sensitivity. The reasons were not fully clear, whether physiological or otherwise, but the probability that these conditions created a heightened individual awareness of building related symptoms could be relevant to the observation. In this respect, we also think that women are marginally more attuned than men, which could account for some of the excess in symptom prevalence reported among women in our study.

The affected workers were noted to self report high levels of social and organisational stress. Studies have shown that many factors in the workplace can be stressful emotionally and physically. ${ }^{28}{ }^{29}$ Job role ambiguity, unreasonable deadlines, and interpersonal conflicts form just three of the many scenarios that might create various stressors, causing discontent at work. Even the same stressor could elicit very different reactions in different people. Although a high level of stress would motivate some to work harder, it might also provoke psychosomatic responses and make those with lowered thresholds of tolerance assume a sick role. As psychosocial ailments could occur irrespective of any real building problems, it is likely that for some people, improving ventilation or indoor air quality would not significantly ameliorate their symptoms.

Our survey confirmed the occurrence of sick building syndrome and its risk factors in the tropics. ${ }^{30}$ It also identified the need for further studies of building associated illness in the tropics. We think that the office workers who reported symptoms were expressing susceptibility to a total environmental burden consisting of the many factors acting independently. We therefore recommend a biopsychosocial approach to the problem involving symptomatic treatment, environmental control, good ergonomic design, and stress management. 
Physicians should consider these possibilities in their patients who regularly seek treatment for non-specific building related symptoms. ${ }^{8}$

We thank Dr K C Chia, Ms G H Quek, and Ms K W Chong of the Ministry of the Environment, Dr G Y Wang and Dr Y C Lin of the Singapore Institute of Standards and Industrial Research, and Professor Y C Chan, Professor T K Tan, Dr T C Tan, and Ms K Char of the National University of Singapore, for their professional and technical assistance with this study.

\section{Appendix: Survey questions on symptoms related to sick building syndrome among office occupants}

Please indicate your experience of the following symptoms at work during the past four weeks:

Fatigue-Daily / 2-3 times weekly / Less

Headache-Daily / 2-3 times weekly / Less

Drowsiness-Daily / 2-3 times weekly / Less

Dizziness-Daily / 2-3 times weekly / Less

Shortness of breath-Daily / 2-3 times weekly / Less

Nausea/vomiting-Daily / 2-3 times weekly / Less

Stuffy nose-Daily / 2-3 times weekly / Less

Dry throat-Daily / 2-3 times weekly / Less

Skin dryness/rash-Daily / 2-3 times weekly / Less Less

Eye irritation-Daily / 2-3 times weekly /

Please state the number of days in the past four weeks that you had to take off work because of these complaints:

When do these complaints occur?

Mornings / Afternoons / No noticeable trend

When do you experience relief from these complaints?

After I leave my workstation / After I leave the building / Never

Please indicate if you have any of these medical conditions:

Asthma? - Yes, on medication / Yes, not on medication / No

Allergy? - Yes, on medication / Yes, not on medication / No

Sinus? - Yes, on medication / Yes, not on medication / No

Migraine? - Yes, on medication / Yes, not on medication / No

Other? (please specify)- Yes, on medication / Yes, not on medication / No

1 Mandell MJ, Fine L. Building ventilation and symptomswhere do we go from here [editorial]? Am $\mathcal{F}$ Public Health 1994;84:347-8.

2 Hoge CW, Breiman RF. Advances in epidemiology and control of legionella infections. Epidemiol Rev 1991;13:329-40.

3 Jaakkola JJ, Miettinen P. Type of ventilation system in office buildings and sick building syndrome. Am $\mathcal{f}$ Epidemio 1995;141:755-65.
4 Kreiss $\mathrm{K}$. The sick building syndrome in office buildings: a breath of fresh air [editorial]. N Engl f Med 1993;328:8778 .

5 Ooi PL, Heng BH, Goh KT. Surveillance of legionellosis in Singapore. In: Chan YC, Goh KT, eds. Travel health. Singapore: Asia Pacific Travel Health Association, 1993: $327-36$

6 Heng BH, Goh KT, Ng LK. Surveillance and control of legionella bacteria in the built environment. In: Goh KT, Ooi PL, eds. Health and the built environment. Singapore: Institute of Environmental Epidemiology, 1995:187-95.

7 Ministry of the Environment. Code of practice for the control of legionella bacteria in air-conditioning cooling towers in Singapore. Singapore: Ministry of the Environment, 1992.

8 Ooi PL, Goh KT, Heng BH, et al. Epidemiological investigations into an outbreak of building-associated illness in Singapore. Asia Pac F Public Health 1994,7:201-5.

9 Quarantine and Epidemiology Department. Outbreak of an unusual illness in a building. In: Communicable disease surveillance in Singapore, 1995. Singapore: Ministry of the Environment, 1996.

10 Samet JM. Indoor air pollution: a public health perspective. Proceedings of the 6th International Conference on Indoor Air Quality. Helsinki: International Conference on Indoor Air Quality 1993;1:3-12.

11 Valbjorn $\mathrm{O}$, Hagen $\mathrm{H}$, Kukkonen $\mathrm{E}$, et al. Indoor climate and air quality problems-investigation and remedy. Horsholm: air quality problems - investigation and remedy.

12 World Health Organisation. Indoor air pollutants: exposure and health effects. Copenhagen: WHO Regional Office for Europe, 1983. (EURO Reports and Studies No 78)

13 Burge PS. Sick building syndrome: causes and economic consequences. In: Goh KT, Ooi PL, eds. Health and the built environment. Singapore: Institute of Environmental Epidemiology, 1995;25-36.

14 [Editorial]. Sick building syndrome. Lancet 1991; 338: $1493-4$

15 McCarthy JF, Bearg DW, Spengler JD. Assessment of indoor air quality. In: Samet JM, Spengler JD, eds. Indoor air pollution: a health perspective. Baltimore: Johns Hopkins University, 1991:285-305.

16 American Conference of Governmental Industrial Hygienists. Guidelines for the assessment of bioaerosols in the indoor environment. ACGIH, Cincinnati, 1989.

17 Seifert B, Knoppel H, Lanting RW, et al. Strategy for sampling chemical substances in indoor air. Luxembourg: Commission of the European Communities, 1989;4-28.

18 Gardner MJ, Altman DG. Statistics with confidence confidence intervals and statistical guidelines. London: BMJ, 1989:28-63.

19 Glantz SA, Slinker BK. Primer of applied regression and analysis of variance. New York: McGraw Hill, 1990:512-68.

20 American Society of Heating, Refrigerating and Airconditioning Engineers. Standard 55-92: Thermal environment conditions for human occupancy. ASHRAE, Atlanta, 1992

21 Ministry of the Environment. The Singapore green plan: towards a model green city. Singapore: Ministry of the Environment, 1993.

22 Ministry of the Environment, Singapore. Guidelines for good indoor air quality in office premises. Singapore: Institute of Environmental Epidemiology, 1996.

23 Abbritti G, Muzi G, Accattoli MP, et al. High prevalence of sick building syndrome in a new air-conditioned building in Italy. Arch Environ Health 1992;47:16-22.

24 Hodgson MJ, Frohliger J, Permar E, et al. Symptoms and microenvironmental measures in nonproblem buildings. $\mathcal{f}$ Occup Med 1991;33:527-33.

25 Jaakkola JJK, Heinonen OP, Seppanen O. Mechanical ventilation in office buildings and the sick building syndrome. An experimental and epidemiological study. Indoor Air 1991;1:111-21

26 Stenberg B, Wall S. Why do women report "sick building symptoms" more often than men? Soc Sci Med 1995;40: 491-502.

27 Weiss B. Low-level chemical sensitivity: a perspective from behavioral toxicology. Toxicol Ind Health 1994;10:605-17.

28 Tay LK. Stress management at the workplace. In: Jeyaratnam J, Chia KS. Occupational health in national development. Singapore: World Scientific, 1994:114-28.

29 Baker DB. Social and organizational factors in office building-associated illness. Occup Med 1989;4:607-24.

30 Ooi PL, Goh KT. Sick-building syndrome in a tropical city. Lancet 1996;347:841-2. 